Tema: Materiais Cerâmicos, Compósitos e Poliméricos

\title{
ESTUDO COMPARATIVO DAS PROPRIEDADES MECÂNICAS DO CONCRETO PADRÃO E CONCRETO COM ADIÇÃO DE FIBRAS VEGETAIS ${ }^{*}$
}

\section{Resumo}

\author{
Leonardo Lúcio de Araújo Gouveia ${ }^{1}$ \\ Ricardo Luiz Perez Teixeira² \\ Carlos Augusto de Souza Oliveira ${ }^{3}$ \\ Bruno Henrique Moreira Ferreira ${ }^{4}$ \\ Sheron Stephany Tavares ${ }^{5}$ \\ Carla Regina Ferreira ${ }^{6}$
}

Este trabalho objetiva o estudo da influência da adição de fibras vegetais de bambu e cana-deaçúcar nas propriedades mecânicas do concreto. Para este trabalho foram confeccionados corpos-de-prova cilíndricos e prismáticos nos quais foram adicionados $2 \%$ e $5 \%$ em volume das fibras à massa do concreto. Após a cura, conforme NBR 5738 (2003) [1], os mesmos foram testados via ensaios de resistência à compressão conforme NBR 5739 (2007) [2], resistência à tração por compressão diametral, conforme NBR 7222 (2011) [3], resistência à tração na flexão conforme NBR 12142 (2010) [4] e módulo de elasticidade estático, conforme NBR 8522(2008) [5]. Verificou-se após os testes que todos os concretos produzidos atenderam a resistência mínima a compressão de $20 \mathrm{MPa}$, recomendado pela NBR 6118 (2003) [6] para fins estruturais. Foi observado um aumento da resistência à compressão em relação à mistura padrão. $O$ concreto com adição de fibras de bambu apresentou melhor resistência mecânica em relação ao concreto com adição das fibras de cana-de-açúcar e ao concreto sem adição.

Palavras-chave: Concreto; Fibras; Propriedades mecânicas; Construção civil.

\section{COMPARATIVE STUDY OF THE MECHANICAL PROPERTIES OF THE CONCRETE WITHOUT ADDITION OF FIBERS AND CONCRETE WITH ADDITION OF VEGETABLE FIBERS \\ Abstract}

This work aimed to study the influence of the addition of vegetable fibers from bamboo and sugar cane on the mechanical properties of concrete. Implementing the same body-of-proof cylindrical and prismatic, which were added $2 \%$ to $5 \%$ per volume of fibers to the mass of concrete were made. After healing according to NBR 5738 (2003) [1], they were tested by testing of compressive resistance, according to NBR 5739 (2007) [2], tensile strength by diametric compression according to NBR 7222(2011) [3], tensile strength in bending according to NBR 12142 (2010) [4] and static modulus, according to NBR 8522(2008) [5]. It was found after testing all concretes produced met the minimum strength of $20 \mathrm{MPa}$ recommended by NBR 6118 (2003) [6] for structural purposes. An increased compression resistance compared to the standard mixture was observed. The concrete with added bamboo fibers showed better mechanical strength compared to concrete with the addition of sugar cane sugar and plain concrete fibers.

Keywords: Concrete; Fiber; Mechanical properties; Civil construction.

1 Mestre em geografia, professor de geologia, departamento de Engenharia Metalurgica, Universidade do Estado de Minas Gerais, Campus Faenge, João Monlevade, Minas Gerais, Brasil.

2 Doutor em engenharia metalúrgica e de Materiais pela UFRJ, professor de materiais metálicos pela Universidade Federal de Itajubá, Campus Avançado de Itabir, Minas Gerais, Brasil.

3 Doutor em Engenharia Metalúrgica e de Minas pela UFMG, professor do curso de Engenharia da Mobilidade pela Universidade Federal de Itajubá, Campus Avançado de Itabira, Minas Gerais, Brasil.

4 Graduando em engenharia civil, Universidade do Estado de Minas Gerais, Campus Faenge, João Monlevade, Minas Gerias, Brasil.

5 Graduanda em engenharia metalúrgica, Universidade do Estado de Minas Gerais, Campus Faenge, João Monlevade, Minas Gerias, Brasil.

6 Graduanda em engenharia metalúrgica, Universidade do Estado de Minas Gerais, Campus Faenge, João Monlevade, Minas Gerias, Brasil.

\footnotetext{
* Contribuição técnica ao 69 Congresso Anual da ABM - Internacional e ao 14ํㅡㄹ ENEMET - Encontro Nacional de Estudantes de Engenharia Metalúrgica, de Materiais e de Minas, 21 a 25 de julho de 2014, São Paulo, SP, Brasil.
} 


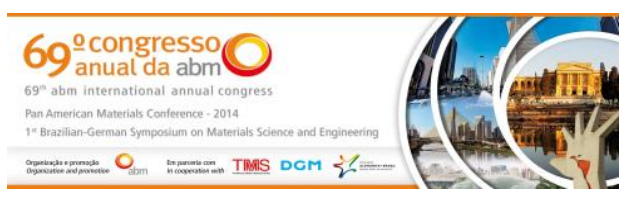

\section{INTRODUÇÃO}

O concreto é o material mais empregado na construção civil. Ele é composto de cimento, agregado miúdo, agregado graúdo, água e eventualmente aditivos químicos e adições, conforme explica França [7] Ao longo dos anos o concreto vem sendo aperfeiçoado, o emprego de fibras vegetais como reforço da matriz cimentícia é um exemplo.

As principais vantagens da utilização dos concretos reforçados com vibras vegetais, (CRFV), advêm do baixo custo de obtenção e de suas características adequadas ao emprego como reforço de materiais frágeis, afirma Zhu et al. [8]. Outro fator importante da utilização dos CRFV se deve ao fato de serem recursos naturais renováveis, e, portanto, não degrada o meio ambiente.

Para Tezuka [9], a adição de fibras à mistura é uma maneira eficiente de se conferir ao concreto maior resistência à tração, ao impacto, à fadiga, melhor tenacidade e ductilidade. Segundo Taylor [10], as fibras não impedem a formação de fissuras nos compósitos, mas, são capazes de aumentar a resistência à tração pelo controle da propagação de fissuras.

Num concreto sem a adição de fibras, quando surge a primeira fissura, sua abertura progressiva dá origem ao colapso da matriz. Contudo, em compósitos com a presença de fibras, essa fratura é retardada. A ruptura torna-se um processo progressivo, pois as pontes de transferências formadas pelas fibras absorvem parte das solicitações e dão origem a uma fissuração mais distribuída.

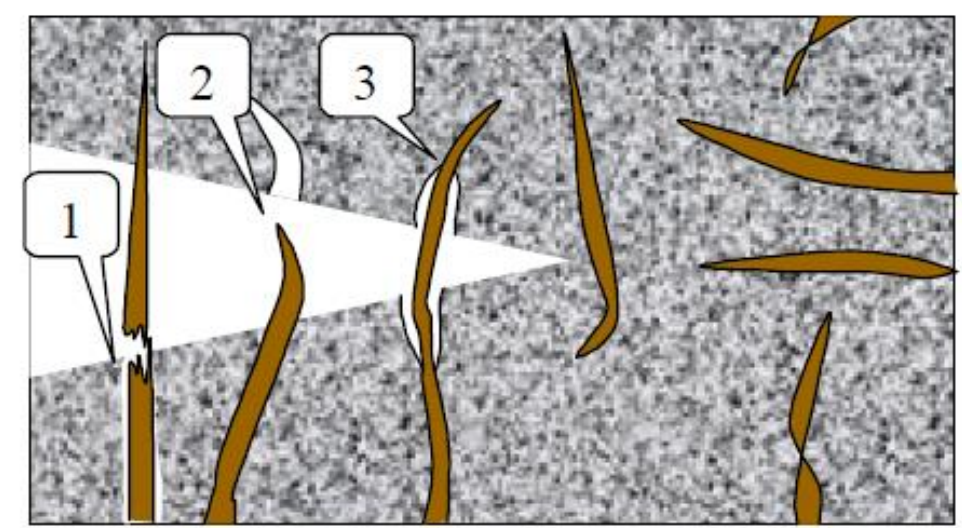

Figura 1. Representação esquemática de uma fissura através de um material compósito reforçado com fibras [11].

A Figura 1 acima mostra a representação de uma fissura atravessando um compósito reforçado com fibras, onde: o número (1) representa uma fibra rompida; o (2) representa uma fibra arrancada; enquanto o (3) representa uma fibra íntegra atravessando a fissura. A fibra (2) exemplifica um caso onde a fibra escorrega da matriz. No caso apresentado da fibra (3), a mesma se apresenta íntegra, absorvendo parcialmente a energia a qual o material está submetido.

A utilização das fibras vegetais como material de reforço ao concreto tem se mostrado positivo em muitos aspectos, no entanto, é necessário consolidar este estudo. Buscou-se através deste trabalho avaliar a influência da adição das fibras de bambu e cana-de-açúcar nas propriedades mecânicas do concreto através dos ensaios de compressão, compressão diametral, tração na flexão e módulo de elasticidade.

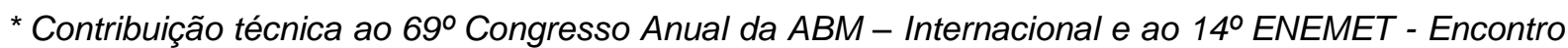
Nacional de Estudantes de Engenharia Metalúrgica, de Materiais e de Minas, 21 a 25 de julho de 2014, São Paulo, SP, Brasil.
} 


\section{MATERIAL E MÉTODOS}

Para execução prática deste trabalho foram confeccionados corpos de provas de concreto cilíndricos e prismáticos. Também realizou-se a caracterização de todos os insumos utilizados na confecção dos corpos-de-prova

\subsection{Cimento}

Foi utilizado o cimento Portland CP-IV 32 RS, conforme NBR 5736 [12]. A tabela 1 apresenta as exigências físicas do aglomerante utilizado nas misturas dos concretos.

Tabela 1. Caracterização do cimento [13]

\begin{tabular}{|c|c|c|c|c|c|c|c|c|c|c|c|c|}
\hline \multirow{2}{*}{$\begin{array}{l}\text { Tipo de } \\
\text { cimento } \\
\text { portland }\end{array}$} & \multirow[b]{2}{*}{ Classe } & \multicolumn{2}{|c|}{ Finura } & \multicolumn{2}{|c|}{ Tempos de pega } & \multicolumn{2}{|c|}{ Expansibilidade } & \multicolumn{5}{|c|}{ Resistência à compressão } \\
\hline & & $\begin{array}{c}\text { Resíduo } \\
\text { na peneira } \\
\text { de } 75 \mathrm{~mm} \\
(\%)\end{array}$ & $\begin{array}{c}\text { Água } \\
\text { específica } \\
\left(\mathrm{m}^{2} / \mathrm{Kg}\right)\end{array}$ & Inicio(h) & Fim (h) & $\begin{array}{l}\text { A frio } \\
(\mathrm{mm})\end{array}$ & $\begin{array}{c}\text { A quente } \\
(\mathrm{mm})\end{array}$ & $\begin{array}{c}1 \mathrm{dia} \\
(\mathrm{MPa})\end{array}$ & $\begin{array}{l}3 \text { dias } \\
\text { (MPa) }\end{array}$ & $\begin{array}{l}7 \text { dias } \\
\text { (Mpa) }\end{array}$ & $\begin{array}{c}28 \\
\text { dias } \\
(\mathrm{MPa})\end{array}$ & $\begin{array}{c}91 \text { dias } \\
(\mathrm{MPa})\end{array}$ \\
\hline $\mathrm{CP} I \mathrm{~V}(2)$ & $\begin{array}{l}25 \\
32\end{array}$ & $\leq 8$ & - & $\geq 1$ & $\leq 12^{(1)}$ & $\leq 5^{(1)}$ & $\leq 5$ & - & $\begin{array}{l}\geq 8,0 \\
\geq 10,0\end{array}$ & $\begin{array}{l}\geq 15,0 \\
\geq 20,0\end{array}$ & $\begin{array}{l}\geq 25,0 \\
\geq 32,0\end{array}$ & $\begin{array}{l}\geq 32,0^{(1)} \\
\geq 40,0^{(1)}\end{array}$ \\
\hline
\end{tabular}

(1) Ensaio facultativo; (2) Outras características podem ser exigidas, como calor de hidratação, inibição da expansão térmica devida à relação álcali-agregado, resistência a meios agressivos, tempo máximo de inicio de pega.

\subsubsection{Areia}

A areia quartzosa utilizada neste trabalho é oriunda do Rio Piracicaba- MG. Na Tabela 2 pode-se visualizar a análise granulométrica do agregado miúdo.

Tabela 2. Análise granulométrica da areia

\begin{tabular}{|c|c|c|c|c|c|c|}
\hline \multicolumn{7}{|c|}{ GRANULOMETRIA } \\
\hline \multirow[t]{2}{*}{$\begin{array}{c}\text { Peneiras } \\
\text { ABNT }(\mathrm{mm})\end{array}$} & \multicolumn{2}{|c|}{$\begin{array}{c}\text { Massa retida } \\
(\mathrm{g})\end{array}$} & \multicolumn{3}{|c|}{$\%$ retida individual } & \multirow[t]{2}{*}{$\begin{array}{c}\text { \% retida } \\
\text { acumulada }\end{array}$} \\
\hline & M1 & M2 & M1 & M2 & Md & \\
\hline 4,8 & 0 & 0 & 0,0 & 0,0 & 0 & 0 \\
\hline 2,4 & 0,5 & 0,8 & 0,1 & 0,2 & 0 & 0 \\
\hline 1,2 & 19,5 & 17,3 & 5,3 & 4,8 & 5 & 5 \\
\hline 0,6 & 69,8 & 67,9 & 19,1 & 18,8 & 19 & 24 \\
\hline 0,3 & 149,6 & 146,4 & 48,8 & 40,6 & 45 & 65 \\
\hline 0,15 & 98,3 & 99,2 & 26,8 & 27,5 & 27 & 92 \\
\hline Fundo & 28,7 & 29,2 & 7,9 & 8,1 & 8 & 100 \\
\hline Total & 366,4 & 360,8 & $100 \%$ & $100 \%$ & $100 \%$ & \\
\hline
\end{tabular}

De acordo com a análise granulométrica realizada o agregado miúdo apresentou dimensão máxima característica de 1,2 mm e módulo de finura igual a 1,86.

Demais ensaios de caracterização do agregado miúdo evidenciou que o mesmo possui massa específica de $2660 \mathrm{Kg} / \mathrm{m}^{3}$ e massa específica aparente de $1385 \mathrm{Kg} / \mathrm{m}^{3}$.

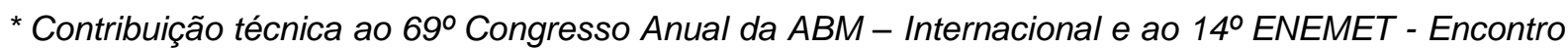
Nacional de Estudantes de Engenharia Metalúrgica, de Materiais e de Minas, 21 a 25 de julho de 2014, São Paulo, SP, Brasil.
} 


\subsubsection{Brita}

O agregado graúdo utilizado neste trabalho é de origem metamórfica (brita de gnaisse). A Tabela 3 mostra a caraterização da brita utilizada neste trabalho.

Tabela 3. Análise granulométrica da Brita

\begin{tabular}{|c|c|c|c|c|c|c|}
\hline \multicolumn{7}{|c|}{ GRANULOMETRIA } \\
\hline $\begin{array}{c}\text { Peneiras } \\
\text { ABNT } \\
(\mathrm{mm})\end{array}$ & Massa retida (g) & \multicolumn{2}{c|}{$\%$ retida individual } & \multirow{2}{*}{$\begin{array}{c}\text { \% retida } \\
\text { acumulada }\end{array}$} \\
\cline { 2 - 7 } & $\mathrm{M} 1$ & $\mathrm{M} 2$ & $\mathrm{M} 1$ & $\mathrm{M} 2$ & $\mathrm{Md}$ & \\
\hline 25,4 & 0 & 0 & 0,0 & 0,0 & 0 & 0 \\
\hline 19 & 387,3 & 346,0 & 7,8 & 7,0 & 7 & 7 \\
\hline 12,5 & 3860,0 & 3466,00 & 77,2 & 69,4 & 74 & 81 \\
\hline 9,6 & 686,3 & 1130,0 & 13,7 & 22,6 & 18 & 99 \\
\hline 6,3 & 58,8 & 49,0 & 1,2 & 1,0 & 1 & 1 \\
\hline Fundo & 7,6 & 9,0 & 0,1 & 0,2 & 0 & 100 \\
\hline Total & 5000 & 5000 & $100 \%$ & $100 \%$ & $100 \%$ & \\
\hline
\end{tabular}

Conforme resultados apresentados na tabela 3 a dimensão máxima característica brita de gnaisse utilizada nessa pesquisa é de $25 \mathrm{~mm}$. Além disso, o agregado possui massa específica absoluta de $2668 \mathrm{~kg} / \mathrm{m}^{3}$ e massa específica aparente de $1356 \mathrm{~kg} / \mathrm{m}^{3}$.

\subsubsection{Fibras}

As fibras utilizadas nesse trabalho foram de bambu e cana-de-açúcar. Antes de serem incorporadas ao concreto elas passaram pelo processo de lavagem com água corrente e foram secas a $(100,0 \pm 0,5)^{\circ} \mathrm{C}$ por 24 horas. As fibras de bambu apresentaram comprimento médio de $(4,5 \pm 0,2) \mathrm{cm}$, enquanto cana-de-açúcar $(3,5 \pm 0,2) \mathrm{cm}$. A Figura 2 mostra as fibras após lavagem e secagem
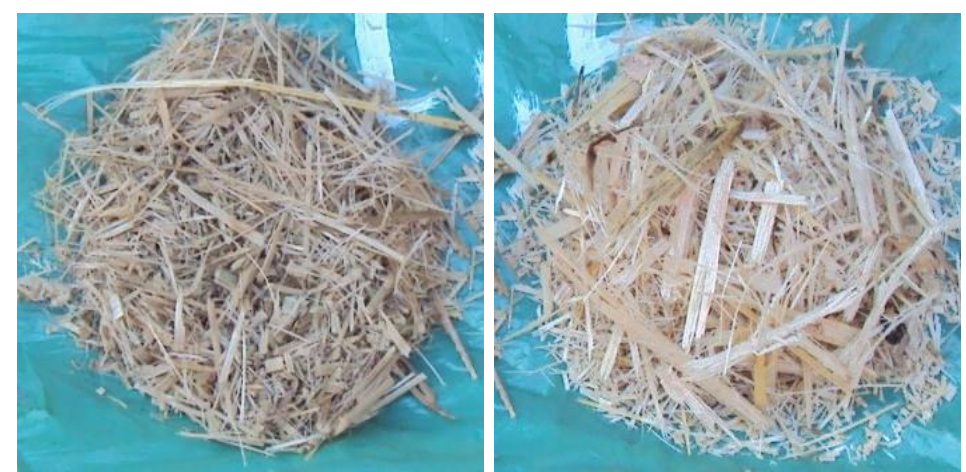

Figura 2. Fibras vegetais de bambu e cana-de-açúcar respectivamente

\subsubsection{Aditivo}

Neste trabalho foi utilizado o aditivo hiperplastificante. Utilizou esse aditivo químico de modo a garantir a trabalhabilidade do concreto quando da inclusão das fibras.

\subsection{Confecção dos Concretos e Moldagem dos Corpos-de-Prova}

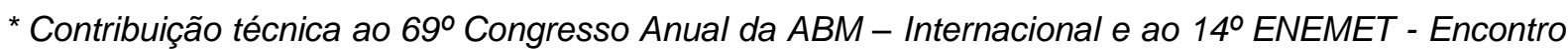
Nacional de Estudantes de Engenharia Metalúrgica, de Materiais e de Minas, 21 a 25 de julho de 2014, São Paulo, SP, Brasil.
} 
Com o objetivo de estudar o comportamento das propriedades mecânicas de resistência do concreto reforçado com fibras vegetais, foram adicionadas $2 \%$ e $5 \%$ de fibras de bambu e cana-de-açúcar à massa concreto. Para o cálculo do traço, a relação água cimento foi de $(0,56 \pm 0,02)$, no entanto, a adição do aditivo interferiu na nesta relação, então a nova razão passou a ser $(0,45 \pm 0,02)$.

$$
\text { 1: } 1,73: 3,34: 0,45
$$

A confecção do concreto foi realizada com o auxílio de uma betoneira de queda livre, as fibras vegetais foram os últimos componentes a serem adicionados na mistura. $A$ Tabela 4 mostra as características dos traços. Como pode ser observado a única alteração ocorrida foi na adição das fibras.

Tabela 4. Características dos traços

\begin{tabular}{|c|c|c|c|c|}
\hline \multirow{2}{*}{ BETONADAS } & \multirow{2}{*}{$\begin{array}{c}\text { TRAÇO } \\
\text { (c: a: b:) Kg }\end{array}$} & \multicolumn{2}{|c|}{ ADIÇÕES } & \multirow{2}{*}{ RUPTURAS } \\
\hline & & Fibras(g) & Aditivo (ml) & \\
\hline $0 \%$ fibra & 6,2: 10,69: 20,67 & 0 & 17,36 & 28 dias \\
\hline $2 \%$ bambu & $6,2: 10,69: 20,67$ & 22,5 & 17,36 & 28 dias \\
\hline $5 \%$ bambu & $6,2: 10,69: 20,67$ & 56,3 & 17,36 & 28 dias \\
\hline 2\% Cana-de-açúcar & $6,2: 10,69: 20,67$ & 28,4 & 17,36 & 28 dias \\
\hline 5\% Cana-de-açúcar & 6,2: 10,69: 20,67 & 71,03 & 17,36 & 28 dias \\
\hline
\end{tabular}

Posteriormente, foram confeccionados 50 corpos de prova cilíndricos nas dimensões de $10 \mathrm{~cm}$ de diâmetro por $20 \mathrm{~cm}$ de altura, bem como 15 corpos de prova prismáticos com seção de $4 \times 4 \mathrm{~cm}^{2}$ e comprimento de $16 \mathrm{~cm}$, conforme ilustrado na Figura 3.
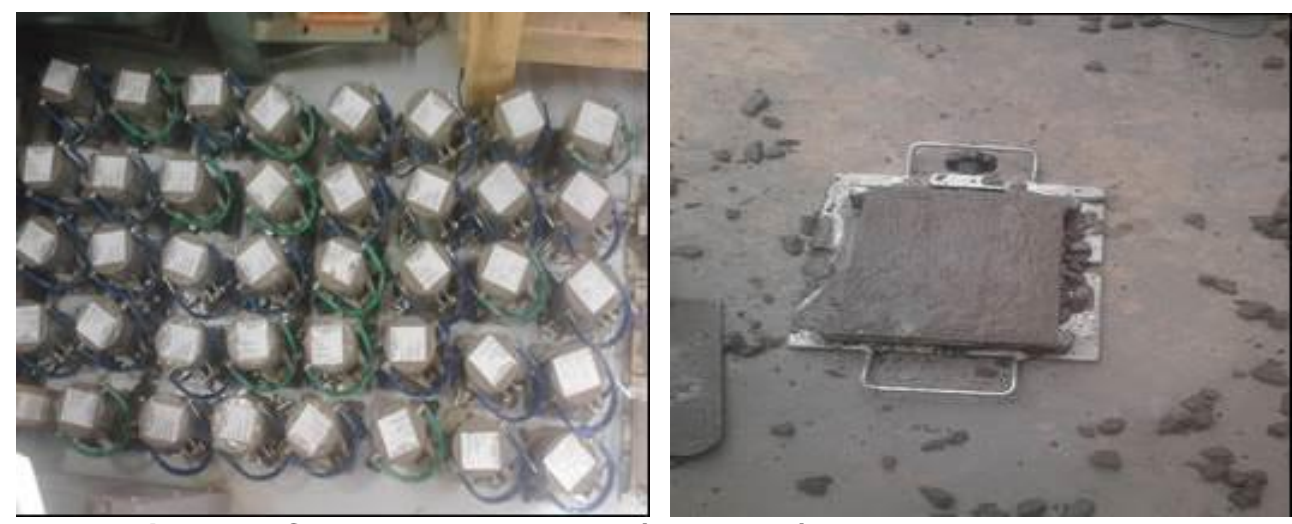

Figura 3. Corpos de prova prismáticos e cilíndricos respectivamente

\subsection{Ensaios Mecânicos}

As avaliações das propriedades mecânicas dos concretos reforçados com fibras vegetais foram obtidas através do ensaio em 65 corpos de provas nas condições de 0\% fibra, 2\% bambu, 5\% bambu, 2\% Cana-de-açúcar e 5\% Cana-de-açúcar de: resistência à compressão; resistência à tração na flexão; resistência à tração por compressão diametral e módulo de elasticidade estático. Em cada ensaio foram utilizados 3 corpos-de-prova para cada percentual citado acima, com exceção do

\footnotetext{
* Contribuição técnica ao 69 Congresso Anual da ABM - Internacional e ao $14^{\circ}$ ENEMET - Encontro Nacional de Estudantes de Engenharia Metalúrgica, de Materiais e de Minas, 21 a 25 de julho de 2014, São Paulo, SP, Brasil.
} 
ensaio de resistência à tração por compressão diametral que utilizou 4 corpos-deprova a cada percentual.

\subsubsection{Resistência à compressão}

O ensaio de compressão axial consiste em determinar a carga máxima de ruptura suportada pelo corpo de prova. Este ensaio segue a NBR 5739(2007).

\subsubsection{Resistência à tração por compressão diametral}

O ensaio é determinado pela ação de duas forças de compressão distribuídas linearmente e diametralmente opostas. Essas ações são fornecidas por uma prensa mecânica, gerando ao longo do diâmetro solicitado, tensões de tração uniformes perpendiculares ao diâmetro do corpo de prova. As forças são aplicadas até que ocorra à ruptura do corpo de prova por tração indireta. Este ensaio segue a NBR 7222 (2011).

\subsubsection{Resistência à tração na flexão}

Para a realização deste ensaio, um corpo-de-prova de seção prismática é submetido à flexão, com carregamentos em duas seções simétricas, até à ruptura. $O$ ensaio também é conhecido por "carregamento nos terços", pelo fato das seções carregadas se encontrarem nos terços do vão. Este ensaio segue a NBR 12142 (2010).

\subsubsection{Módulo de elasticidade estático}

O módulo de elasticidade é a relação entre a tensão aplicada e deformação abaixo de um limite proporcional adotado. O módulo de deformação estático para um concreto sob compressão axial é determinado a partir da declividade da curva tensão-deformação obtida em ensaios de corpos de prova cilíndricos. Este ensaio segue a NBR 8522(2008).

\section{RESULTADOS E DISCUSSÃO}

Neste tópico apresentam-se os resultados obtidos nos ensaios de resistência mencionados anteriormente. Estes dados permitem avaliar as propriedades de resistência do concreto reforçado com fibras de bambu e cana-de-açúcar.

A Figura 4 mostra os dados referentes ao ensaio de resistência à compressão axial. Pode ser observado que o menor valor de resistência à compressão ocorreu no bloco de concreto sem adição de fibras, e o maior valor ocorreu no concreto com adição de $2 \%$ de bambu.

\footnotetext{
* Contribuição técnica ao 69 Congresso Anual da ABM - Internacional e ao $14^{\circ}$ ENEMET - Encontro Nacional de Estudantes de Engenharia Metalúrgica, de Materiais e de Minas, 21 a 25 de julho de 2014, São Paulo, SP, Brasil.
} 

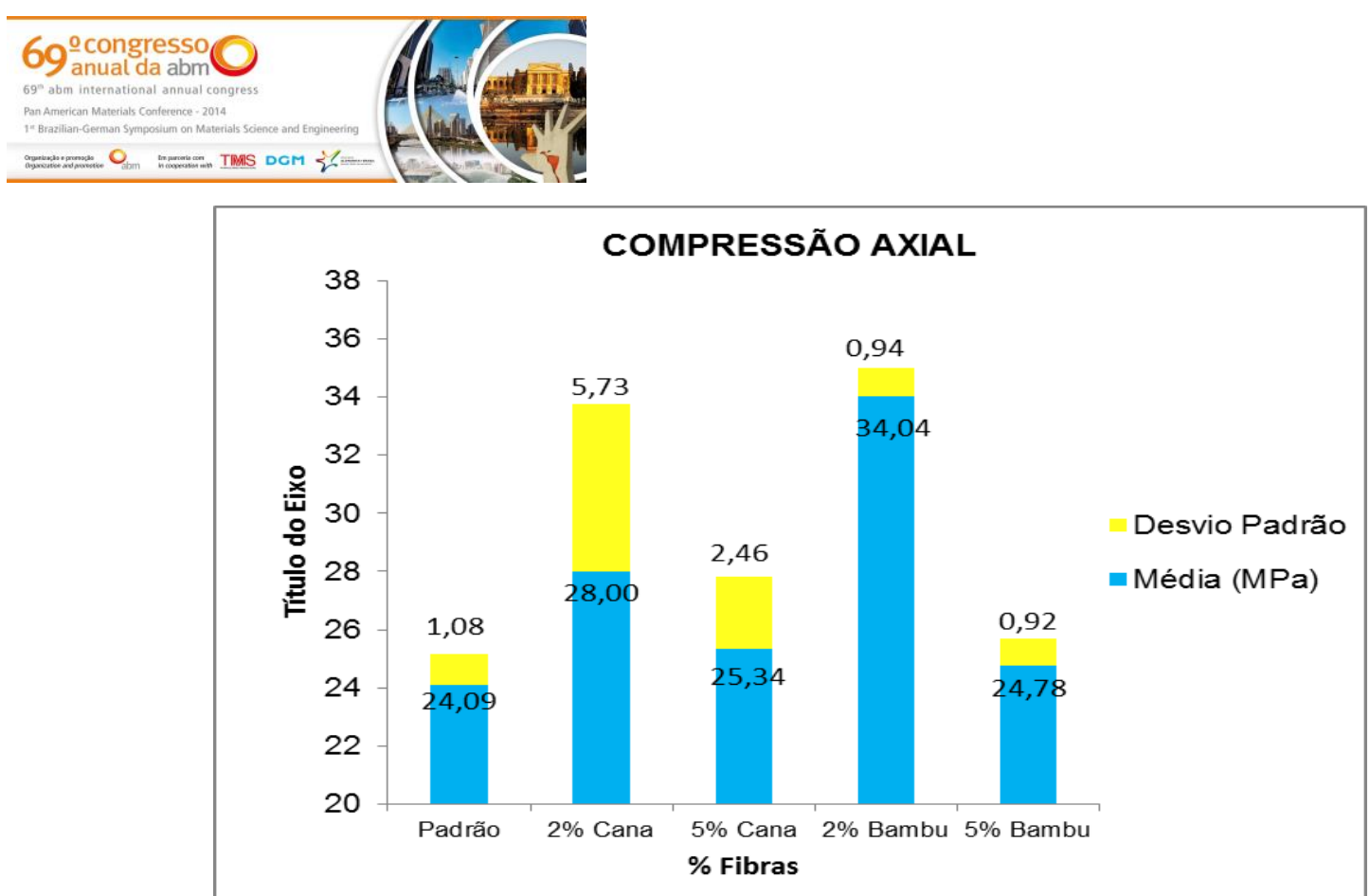

Figura 4. Dados referentes ao ensaio de resistência à compressão axial

A Figura 5 mostra os dados referentes ao ensaio de resistência à tração por compressão diametral. Pode ser observado que o menor valor de resistência também ocorreu no bloco de concreto sem adição de fibras, e o maior valor ocorreu no concreto com adição de $2 \%$ de bambu.

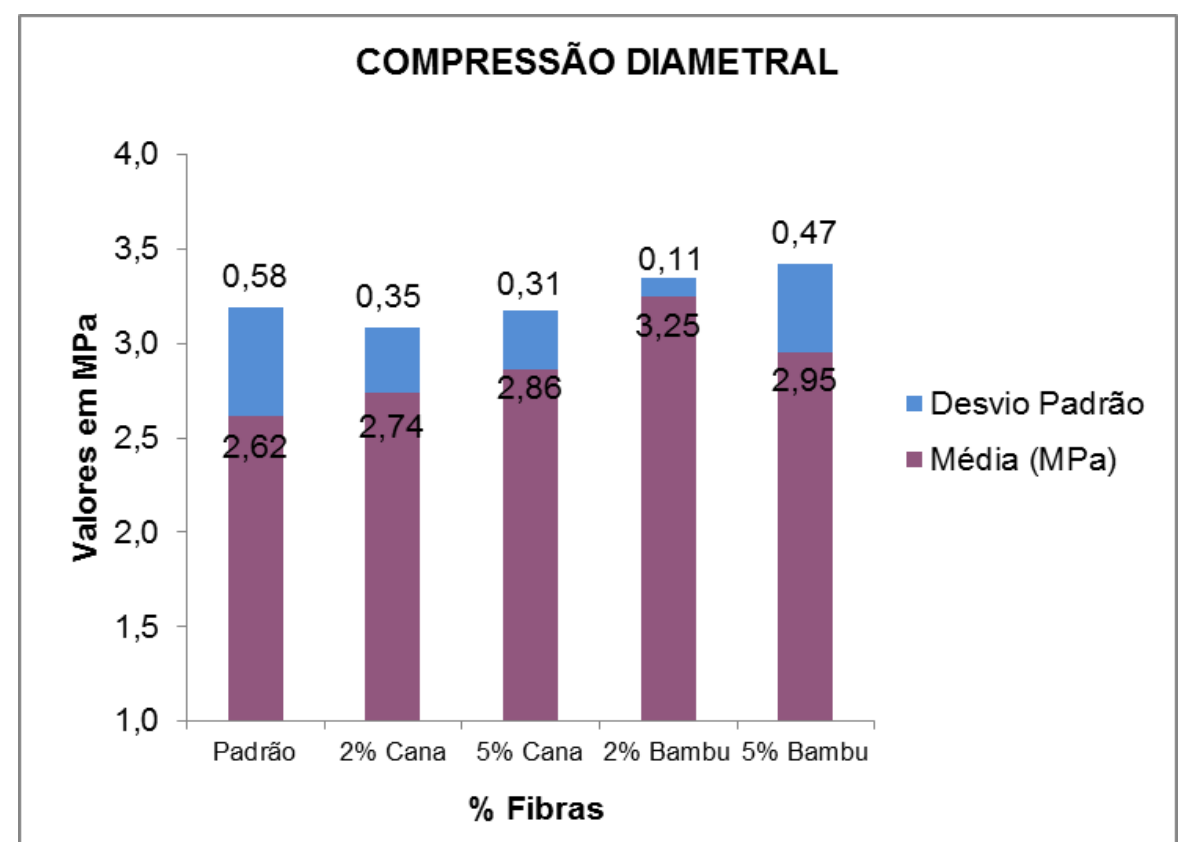

Figura 5. Dados referentes ao ensaio de resistência à tração por compressão diametral

A Figura 6 mostra os dados referentes ao ensaio de resistência à tração na flexão. Pode ser observado que o menor valor de resistência ocorreu no bloco de concreto sem adição de fibras, e o maior valor ocorreu no concreto com adição de $5 \%$ de cana-de-açúcar.

* Contribuição técnica ao 69 Congresso Anual da ABM - Internacional e ao 14ํㅡㄹ ENEMET - Encontro Nacional de Estudantes de Engenharia Metalúrgica, de Materiais e de Minas, 21 a 25 de julho de 2014, São Paulo, SP, Brasil. 

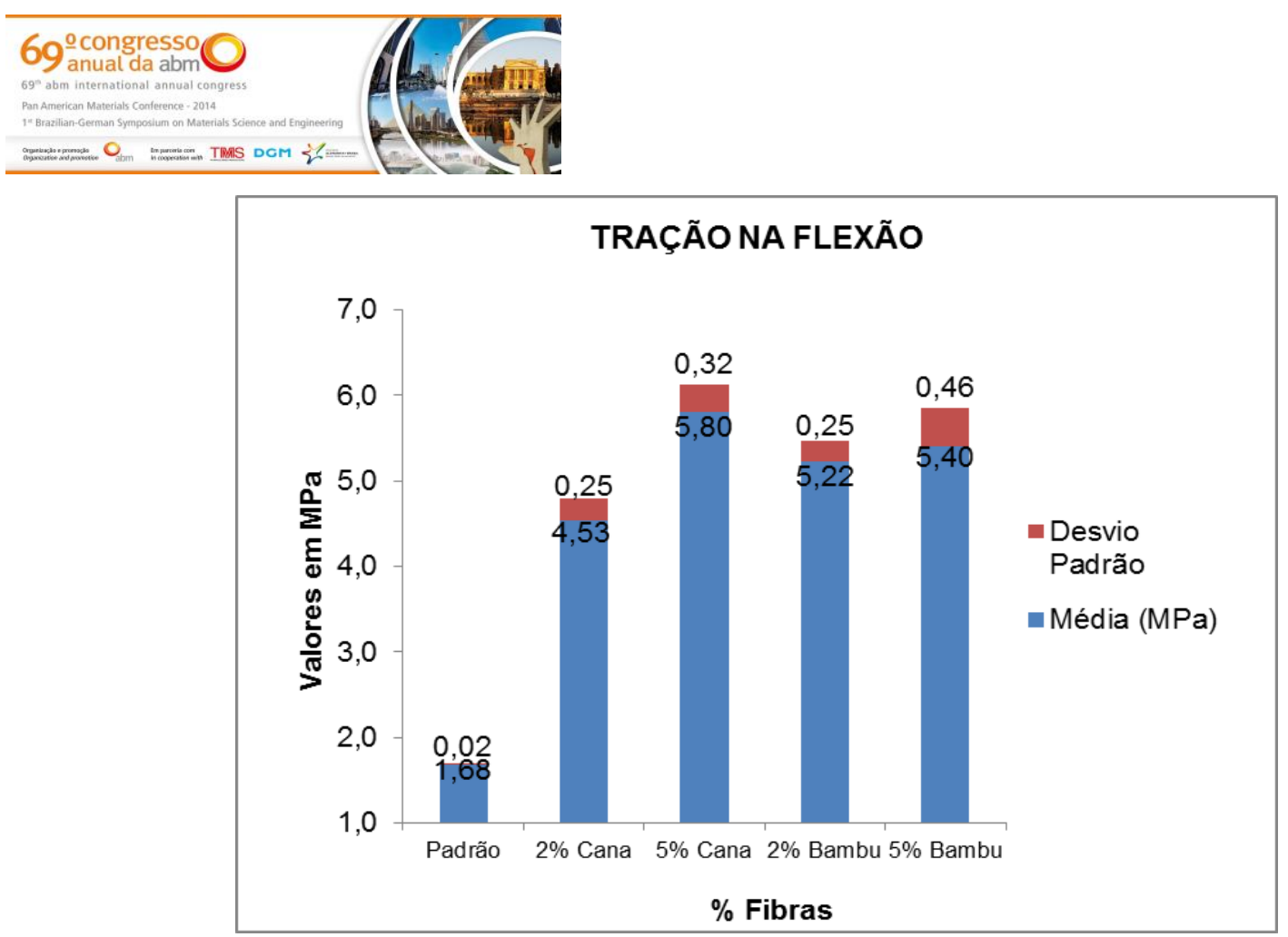

Figura 6. Dados referentes ao ensaio de resistência à tração na flexão

A Figura 7 mostra os dados referentes ao módulo de elasticidade estático. Pode ser observado no gráfico que os valores estão bem equiparados. O maior valor ocorreu com $2 \%$ de bambu e o menor valor ocorreu com $5 \%$ de cana-de-açúcar.

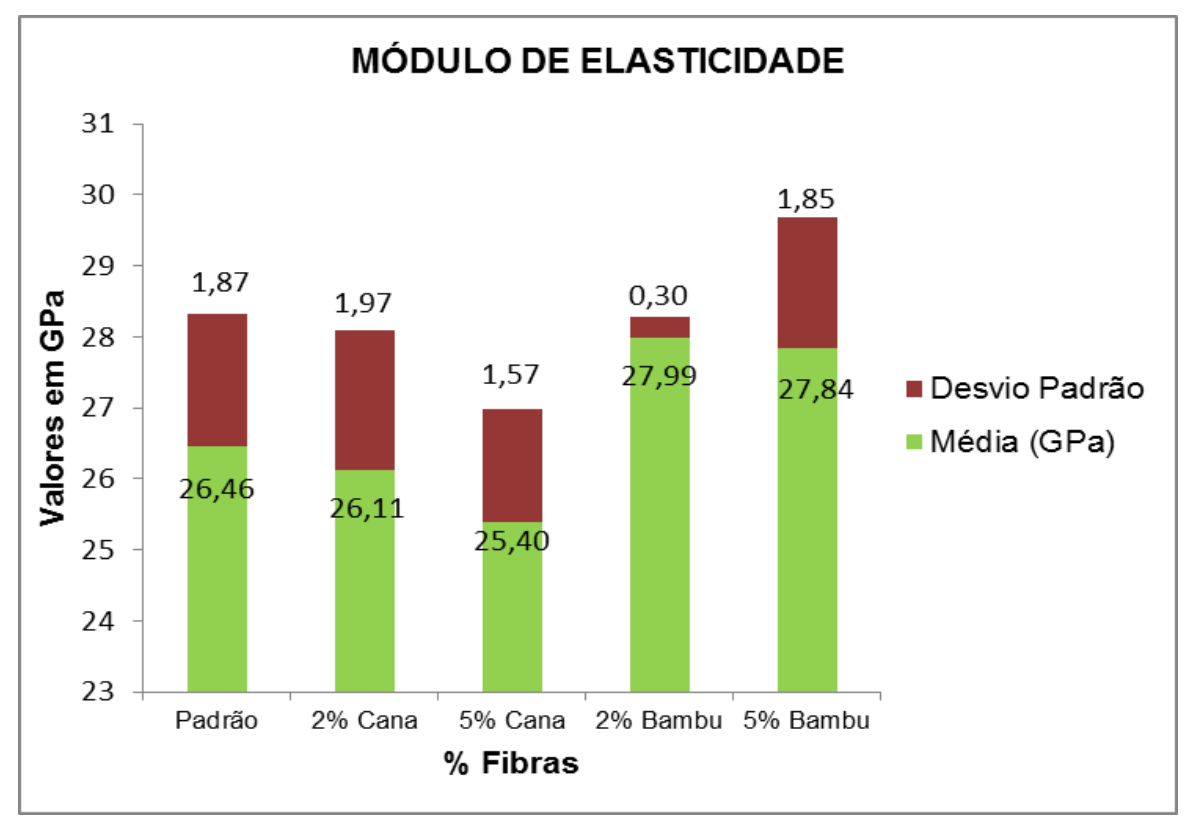

Figura 7. Dados referentes ao módulo de elasticidade estático

A Figura 8 mostra os dados referentes à absorção de água. Pode ser observado no gráfico que os valores estão bem equiparados e que não houve variação significante entre os percentuais obtidos e o desvio padrão foi o mesmo para cada percentual.

\footnotetext{
* Contribuição técnica ao $69^{\circ}$ Congresso Anual da ABM - Internacional e ao $14^{\circ}$ ENEMET - Encontro Nacional de Estudantes de Engenharia Metalúrgica, de Materiais e de Minas, 21 a 25 de julho de 2014, São Paulo, SP, Brasil.
} 

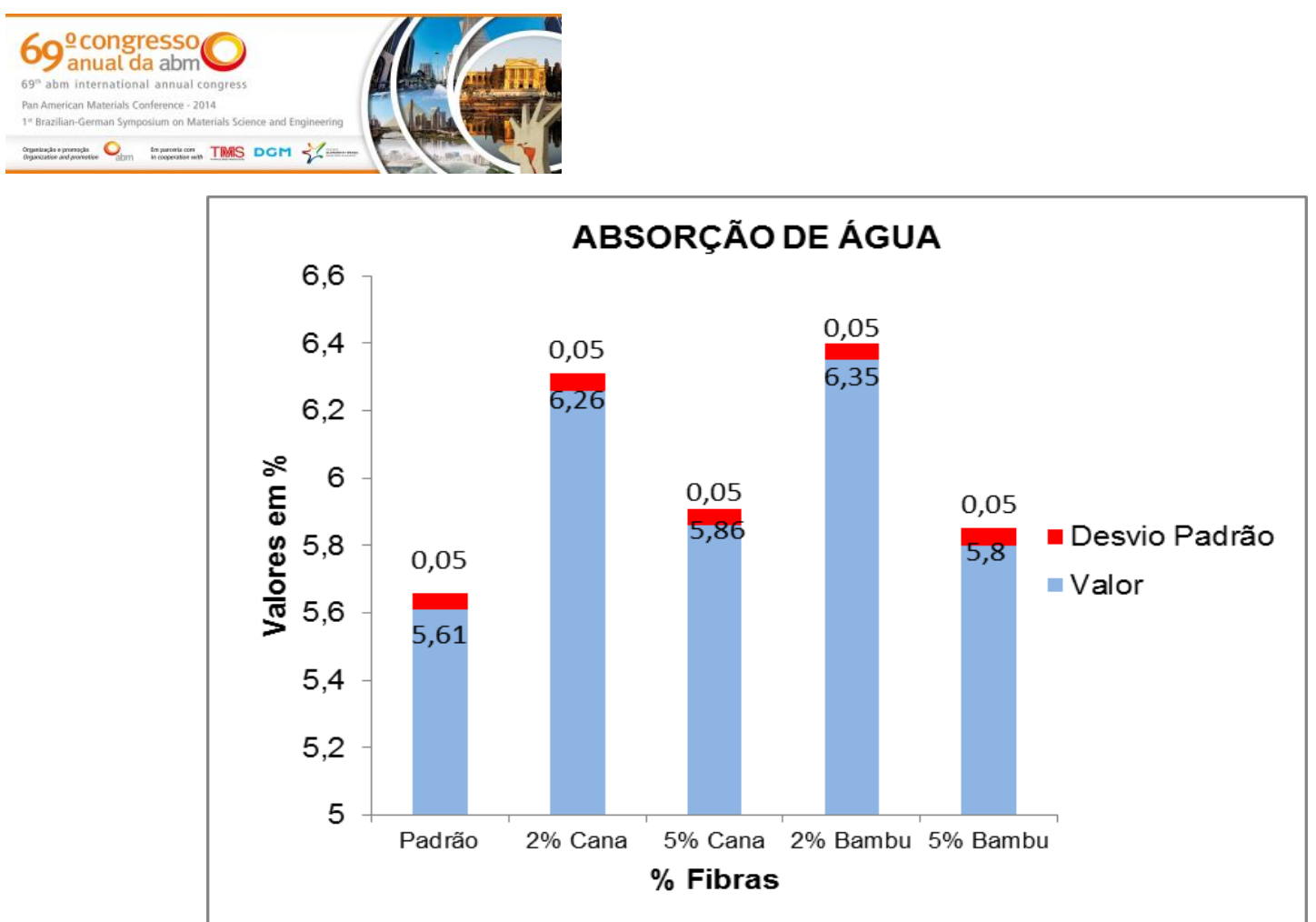

Figura 8. Dados referentes à absorção de água.

\section{CONCLUSÃo}

Segundo testes realizados em laboratório com 65 corpos de prova nas condições de 0\% fibra, 2\% bambu, 5\% bambu, 2\% Cana-de-açúcar e 5\% Cana-de-açúcar, o emprego de fibras vegetais à formulação de concretos é tecnicamente viável. Todos os concretos produzidos atenderam a resistência mínima de $20 \mathrm{MPa}$, estabelecidos pela NBR 6118 (2003) pra fins estruturais. A dosagem dos insumos (areia + cimento + brita + água + aditivo) foi à mesma em todas as misturas, sendo a dosagem das fibras a responsável pelas alterações nos valores obtidos.

No que diz respeito ao ensaio de compressão axial, o melhor resultado foi obtido no concreto com $2 \%$ de bambu, o qual apresentou um aumento de $41 \%$ em relação à mistura padrão e $21,6 \%$ em relação à mesma dosagem com cana-de-açúcar. No ensaio de resistência à tração por compressão diametral o maior valor obtido também foi com o concreto com adição de $2 \%$.

No ensaio de tração na flexão, o concreto com $5 \%$ de cana-de-açúcar foi o que apresentou o melhor resultado, de $(5,8 \pm 0,5) \mathrm{MPa}$, tendo um aumento de $247 \% \mathrm{em}$ relação ao concreto sem adição de fibra e $7 \%$ em relação a mesma dosagem com bambu. No módulo de elasticidade as dosagens de cana tiveram um ligeiro decréscimo, ao contrario das dosagens de bambu, que tiveram um ligeiro aumento. No entanto, os valores obtidos foram próximos ao padrão, sem variação significativa. O resultado do teste de absorção de água mostrou que a variação entre o concreto padrão e o concreto com adição das fibras vegetais foi menor que $1 \%$.

Em virtude dos dados obtidos, os empregos das fibras têm grandes benefícios. Dentro das porcentagens propostas, a mais recomendada é a $2 \%$, sendo essa a detentora dos melhores resultados.

\section{Agradecimentos}

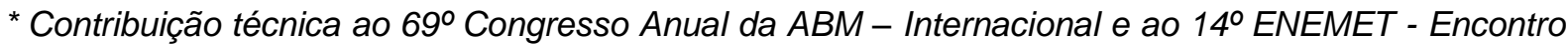
Nacional de Estudantes de Engenharia Metalúrgica, de Materiais e de Minas, 21 a 25 de julho de 2014, São Paulo, SP, Brasil.
} 
Agradecemos ao orientador Prof. Dr. Carlos Augusto de Souza Oliveira, aos técnicos do laboratório de Materiais de Construção Civil da UNIFEI-Itabira, senhores José Geraldo e Antônio;

Agradecemos a Conceição Moreira por ter disponibilizado as fibras para execução deste trabalho.

À UEMG, Campus João Monlevade e à UNIFEI - Campus Avançado de Itabira pelo apoio a pesquisa.

\section{REFERÊNCIAS}

1 Associação Brasileira de Normas Técnicas. NBR 5738: Procedimento para moldagem e cura de corpos-de-prova. Rio de Janeiro; 2003.

2 Associação Brasileira de Normas Técnicas. NBR 5739: Concreto - Ensaios de compressão de corpos-de-prova cilíndricos. Rio de Janeiro; 2007.

3 Associação Brasileira de Normas Técnicas. NBR 7222: Concreto e argamassa Determinação da resistência à tração por compressão diametral de corpos de prova cilíndricos. Rio de Janeiro; 201.

4 Associação Brasileira de Normas Técnicas. NBR 12142 / MB 3483: Concreto Determinação da resistência à tração na flexão em corpos-de-prova prismáticos. (Procedimento). Rio de Janeiro; 1991.

5 Associação Brasileira de Normas Técnicas. NBR 8522: Concreto - Determinação do módulo estático de elasticidade à compressão e Diagrama Tensão-Deformação Método de Ensaio. Rio de Janeiro; 2008.

6 Associação Brasileira de Normas Técnicas. NBR 6118: Projeto de estruturas de concreto - Procedimento. Rio de Janeiro; 2003.

7 França EP. Tecnologia Básica do Concreto [Apostila Curso Engenharia de Produção Civil]. Belo Horizonte: Disciplina materiais de construção. CEFET; 2004.

8 Zhu WH, Tobias BC, Coutts RSP, Langfors G. Air-cured banana fibre reinforced cement composites. Cement and concrete composites. 1994;16(1):3-8.

9 Tezuka Y. Concreto armado com fibras. 2a ed. São Paulo: ABCP; 1999.

10 Tailor GD. Materials in Construction. $2^{\underline{a}}$ Ed. London: Longman Scientific e Thecnical; 1994.

11 Coutts RSP. Sticks and stones...!! Forest products newsletter. CSIRO division of chemical and wood technology. 1986;2(1).

12 Associação Brasileira de Normas Técnicas. NBR 5736: Cimento Portland pozolânico (Especificação). Rio de Janeiro; 1991.

13 ABCP. Guia básico de utilização do cimento Portland. 2002. Disponível em: http://www.abcp.org.br/conteudo/wp-content/uploads/2009/12/BT106_2003.pdf.

\footnotetext{
* Contribuição técnica ao 69 Congresso Anual da ABM - Internacional e ao $14^{\circ}$ ENEMET - Encontro Nacional de Estudantes de Engenharia Metalúrgica, de Materiais e de Minas, 21 a 25 de julho de 2014, São Paulo, SP, Brasil.
} 